\title{
Clinico-Epidemiological Aspects of Telogen Effluvium In Iraqi Women
}

\author{
Basman M. Fadheel* $\quad$ MBChB , FIBMS
}

Abstract:

Fac Med Baghdad

2016; Vol.58, No.3

Received:April.2016

Accepted:July.2016

Background: telogen effluvium is a form of non- scarring alopecia characterized by diffuse hair shedding, often of acute onset. It's a reactive process caused by metabolic or hormonal stress or by medications. Generally, recovery is spontaneous within 6 months.

Objectives: is to shed a light on the clinic- epidemiological aspects and most important causes of telogen effluvium in Iraqi women.

Patients and methods: A total number of 100 female patients were seen in the period between March 2014 to March 2015 in the Dermatology Department of Baghdad Teachinhg Hospital / Medical City. Their ages ranged between 20 to 40 years old and the duration of their complaints ranged between 1 to 12 months. Their symptoms were excessive hair loss, diffuse shedding, scalp hair thinning and trichodynia. In all patients the diagnosis was confirmed by positive pull test, and the patients were questioned about all possible triggering factors.

Results: In most of cases, 74\%,the duration of illness was less than 6 months . all the patients complained of diffuse shedding , $12 \%$ had visibile scalp thinning and only $8 \%$ had trichodynia . In $32 \%$ of cases no underlying triggering factor was identified and $21 \%$ of cases had acute psychological distress.

Conclusion: most of cases of telogen effluvium in Iraqi women were without clear underlying triggering factor, most patients were anxious about impending baldness, but significant hair thinning was present in only minority of patients.

Searching for underlying iron diffeciency is important as $6 \%$ of patients had evidence of subcinical iron diffeciency on laboratory examinations.

Key words: telogen effluvium, triggering factors.

\section{Introduction:}

Telogen effluvium is a form of non scarring alopecia characterized by diffuse hair shedding, often with acute onset . A chronic form with more gradual onset and longer duration also exists $(1,2)$. It's a reactive process caused by metabolic or hormonal stress or by medications. Generally, recovery is spontaneous and usually occurs within 6 months $(1,2)$. It can effects hair on all parts of the body, but generally only loss of scalp hair is symptomatic (1).

Telogen effluvium is triggered when a physiologic stress or hormonal changes cause large number of hair follicles enter the anagen at same time. The interval between the inciting event and the onset of shedding corresponds to the length of telogen phase between 1 and 6 months, average 3 months(2,3).

Morbidity in telogen effluvium is limited to mild cosmetic changes, however, it may cause significant psychological impact and sometimes associated with trichodynia(4,5). The hair is lost diffusely from the entire scalp, however, complete alopecia is not seen(1).

Careful questioning may reveals a metabolic or physiologic stress 1 to 6 monthes before the start of hair shedding. Main

*Dept. of Dermatology and Venereology / College of Medicine/ University of Baghdad.

E-mail,bmflili@yahoo.com physiologic stressors that can induce telogen effluvium include ,febrile illness ,major surgery ,sever diet ,pregnancy and delivery, and some medications $(6,7,8,9,10,11,12,13$,$) .$ Physical findings on examination are spares and usually the examining physician does not appreciate a decrease in hair density, however in patients complaining of hair fall for several months hair may appear thin when compared with old photographs(1). In active telogen effluvium the gentle hair pulling test will yield positive results, where increased number of club hairs come out from the roots upon gentle pulling ,and when active shedding has stopped, hair pulling test will return to normal again and not positive any more(2).

\section{Patients and methods:}

A total number of 100 female patients were seen in the period between March 2014 to March 2015 at the Department of Dermatology and Venereology of Baghdad Teaching Hospital / Medical City. Their ages ranged between 20 to 40 years old and the duration of their complaints ranged between 1 to 12 months. Theircomplain were excessive hair shedding of recent onset.

All patients included in this study were in whom the diagnosis of telogen effluvium was confirmed clinically by positive pull 
test for club hairs. The test was performed by pulling a small bundles of hairs separately, each bundle consists of about 20 to 30 hairs ,the strength of pull was to the degree of inducing moderate discomfort to patient, and when more than $2 \mathrm{club}$ hairs come out with each bundle the test is considered positive .Patients with negative pull test were excluded because of unconfirmed diagnosis of telogen effluvium and other causes of diffuse hair loss could not be excluded. Patients were questioned about all possible triggering factors, including ,history of recent delivery, physical or surgical trauma ,acute psychological insult or stress, acute febrile illness, sever diet ,drug history including oral contraceptive pills discontinuation , and history of any scalp disease like scalp psoriasis or severe seborrhic dermatitis or hair dying and hair dye contact dermatitis.

\section{Results:}

The ages of the patient ranged between 20 to 40 years old and the duration of their complaints ranged between 1 to 12 months with a mean and standard deviation of $3.5 \pm 1.8$ months. In 74 patients $(74 \%)$ the duration of complaints were shorter than 6 months, while in 26 patients $(26 \%)$ the duration were longer than 6 months.

In all 100 patients (100\%) the chief complain was recent onset of excessive hair fall or loss, but only in12 patients (12\%) visible scalp hair thinning was noticed by the patients and only in 8 patients $(8 \%)$ there was trichodynia, which is mild pain or discomfort felt at hair root, when patients were asked specifically about this complain, (table 1$)$.

All patients had significant anxiety about their condition, and it was not

proportional to their degree of hair loss and were preoccupied about going to have severe alopecia .

Regarding the triggering factors, in 38 patients (38\%) no underlying triggering factor could be identified and theses cases were labeled as idiopathic . In 31 patients(31\%) history of recent psychologically stressful event was present . 14 patients (14\%) give recent history of delivery , 7 patients (7\%) history of sever acute febrile illness and 4 patients history of oral contraceptive pills discontinuation. In 4 patients (4\%) there was history of scalp contact dermatitis to hair dye, although during personal observation in this study most of the patients already have a dyed hair but it seems that hair dye alone does not trigger telogen effluvium unless there is associated contact dermatitis

In all patients there was negative surgical or physical trauma or any medications intake (table2). In patients with negative history of any possible triggering factor, especially in menstruating females investigations were done to exclude subclinical iron deficiency including serum iron, serum transferrin and iron binding capacity, and in 6 patients $(6 \%)$ there was subclinical iron deficiency that was most probably the trigger for telogen effluvium in these patients (table2) . In subclinical iron deficiency the patients is asymptomatic for anemia and hematocrit measures like hemoglobin concentration and meas corpuscular volume could be normal.

Table 1:, symptoms and complains of patients with telogen effluvium .

\begin{tabular}{ccc}
\hline Symptom & $\begin{array}{c}\text { No. of patients } \\
\text { involved }\end{array}$ & $\begin{array}{c}\text { \% of the presence of } \\
\text { symptom }\end{array}$ \\
\hline Shedding & 100 & $100 \%$ \\
\hline Visible scalp thinning & 12 & $12 \%$ \\
\hline Trichodynia & $\mathbf{8}$ patients & $8 \%$ \\
\hline
\end{tabular}

Table 2, causes and triggering factors of telogen effluvium in Iraqi women.

\begin{tabular}{ccc}
\hline Triggering factor & $\begin{array}{c}\text { No. of } \\
\text { patients }\end{array}$ & $\begin{array}{c}\% \text { of the triggering } \\
\text { factor }\end{array}$ \\
\hline Postpartum & 14 & $14 \%$ \\
\hline $\begin{array}{c}\text { Discontinuation of oral } \\
\text { contraceptive pills }\end{array}$ & 4 & $4 \%$ \\
\hline Acute febrile illness & 7 & $7 \%$ \\
\hline Major surgery & 2 & $2 \%$ \\
\hline $\begin{array}{c}\text { Acute psychological stress or } \\
\text { trauma }\end{array}$ & 31 & $31 \%$ \\
\hline Medications & 0 & $0 \%$ \\
\hline Iron deficiency & 6 & $6 \%$ \\
\hline Hair dye contact dermatitis & 4 & $4 \%$ \\
\hline idiopathic & 32 & $32 \%$ \\
\hline Total no. & 100 & 100 \\
\hline
\end{tabular}

\section{Discussion:}

Telogen effluvium is a common dermatological problem encountered in daily dermatological practice. Its characterized by diffuse hair shedding often with acute onset and duration that usually last for up to months. It is usually occurs as a result of some triggering insults that lead a large number of hair follicles to enter telogen phase at the same time. In this study, most of our cases the duration of the condition was less than 6 months (74\%) of cases and only (26\%) of cases were more than 6 months . these results are compatible with previous studies, and are related to the fact that most of triggering factors for telogen effluvium are acute or transient in nature $(1,2)$ Regarding patients symptoms and complains , all patients presented complaining of excessive hair shedding and were anxious about progressive hair loss and impending baldness , but only $12 \%$ of patients had visible scalp thinning upon examination and $8 \%$ admitted to have trichodynia when they were specifically asked. Therefore in most of our patients, telogen effluvium, could cause substantial psychological 
impact and anxiety that could be not proportional to the degree of hair loss. These facts have the flowing significance, first this psychological impact could aggravate the telogen effluvium if it was sever, secondly, it is very important regarding management to give the patient reassurance and good explanation about the transient nature of the disease and that there is no impending baldness is going to occur. For the triggering factors in our study, $32 \%$ of patients had no underlying triggering factor, so, there were labeled as idiopathic , and this result is consistent with previous studies (11,12 ). Acute psychological stress or trauma was the most important triggering factor in our patients, which contribute to $31 \%$ of cases in our patients and when all other possible concomitant triggering factors could not be revealed. Results of this study and other previous studies indicates that psychological stress can induce catagen and telogen in hair follicles and this may be related to to release and effect of certain neurotransmitters and Stress related hormones or substances (6). Stress may act as primary inducer or aggravating factor in the presence of other triggering factor, and the results of studies on association of stress with telogen effluvium is agreeable with results in this study $(13,14,15)$. Subclinical iron deficiency is important triggering factor that should be looked for specifically by doing appropriate laboratory especially whe no clear triggering factor could be identified, and especially in cases of telogen effluvium that last for more than 6 months with tendency for chronicity and especially with history of heavy menstruation or poor dietry habits with low iron intake(16) . In our study $6 \%$ of our patients with telogen effluvium was attributed to iron deficiency ,although the results of previous studies were not conclusive $(17,18)$, while other study demonstrated higher association between telogen effluvium and iron deficiency (19).Complete blood counts could be normal in women with mild iron deficiency anemia. Blood is more essential than hair and has the priority for stored iron, and hence, hair may start to shed before red blood cells Indices become microcytic (20). Although low serum ferritin is proof of iron deficiency, a normal level does not exclude iron deficiency and further confirmation can be done by depending on iron saturation as the most sensitive indicator of iron deficiency (21).

\section{References:}

1. Sinclair R. Chronic telogen effluvium: a study of 5 patients over 7 years. J Am Acad Dermatol. 2005;52(2 Suppl 1):12-6.

2. Whiting DA. Chronic telogen effluvium: increased scalp hair shedding in middle-aged women. J Am Acad Dermatol. 1996;35(6):899-906.

3. Headington JT. Telogen effluvium. New concepts and review. Arch Dermatol. 1993;129(3):356-63.

4. Cartwright T, Endean N, Porter A. Illness perceptions, coping and quality of life in patients with alopecia. $\mathrm{Br} J$ Dermatol. 2009;160(5):1034-9.
5. Schmidt S, Fischer TW, Chren MM, Strauss BM, Elsner P. Strategies of coping and quality of life in women with alopecia. Br J Dermatol. 2001;144(5):1038-43.

6. Hadshiew IM, Foitzik K, Arck PC, Paus R. Burden of hair loss: stress and the underestimated psychosocial impact of telogen effluvium and androgenetic alopecia. J Invest Dermatol. 2004;123(3):455-7.

7. Peters EM, Liotiri S, Bodo E, et al. Probing the effects of stress mediators on the human hair follicle: substance P holds central position. Am J Pathol. 2007;171(6):1872-86.

8. Freinkel RK, Freinkel N. Hair growth and alopecia in hypothyroidism. Arch Dermatol. 1972;106(3):349-52.

9. Goette DK, Odom RB. Alopecia in crash dieters. JAMA. 14 1976;235(24):2622-3.

10. Kantor J, Kessler LJ, Brooks DG, Cotsarelis G. Decreased serum ferritin is associated with alopecia in women. J Invest Dermatol. 2003;121(5):985-8.

11. Harrison S, Sinclair R. Telogen effluvium. Clin Exp Dermatol 2002;27:389-5.

12. Sinclair RD, Banfield CC, DDawber RP. Diffuse hair loss. In: Sinclair RD, Banfield CC, Dawber RP editors. Handbook of diseases of the hair and scalp. UK: Blackwell Science Ltd; 1999. p. 64-74.

13. Bosse KA, Gieler U. Seelische Faktorenbei Haustkrankheiten: Beitra" gezurpsychosomatischen Dermatologie. Bern: Verlag Hans Huber; 1987.

14. Botchkarev VA. Stress and the hair follicle: Exploring the connections. Am J Pathol 2003;162:709-12.

15. Paus R. Stress, hair growth control and the neuro-endocrine immune connection. Allergol J 2000;9:611-20.

16. Dawber RPR, Simpson NB, Barth JH. Diffuse alopecia: Endocrine, metabolic and chemical influences on the follicular cycle. In: Dawber RP, editor. Diseases of the Hair and Scalp. Oxford: Blackwell Science; 1997. p. 123-50.

17. Trost LB, Bergfeld WF, Calogeras E. The diagnosis and treatment of iron deficiency and its potential relationship to hair loss. J Am Acad Dermatol 2006;54:824-44.

18. Sinclair $R$. There is no clear association between low serum ferritin and chronic diffuse telogen hair loss. Br J Dermatol 2002;147:982-4.

19. Fatania M. I. et al . Prevelence and Fators Associated with Telogen Effluvium in Adult Females at Mekkah region, Saudi Arabia.A Retrospective Study. JDDS. 2018 Volume 19, Issue 1 , page $27-30$

20. Trost LB, Bergfeld WF, Calogeras E. The diagnosis and treatment of iron deficiency and its potential relationship to hair loss. J Am Acad Dermatol. 2006;54(5):824-44.

21. Olsen EA, Reed KB, Cacchio PB, Caudill L. Iron deficiency in female pattern hair loss, chronic telogen effluvium, and control groups. J Am Acad Dermatol. 2010;63(6):991- 